\title{
Interannual and Interdecadal Variability of Thailand Summer Monsoon Season
}

\author{
NKRINTRA SinghratTNA \\ Department of Civil, Environmental and Architectural Engineering, University of Colorado, Boulder, Colorado, and Thailand Public \\ Works Department, Bangkok, Thailand \\ BALAJI RAJAGOPALAN \\ Department of Civil, Environmental and Architectural Engineering, and Cooperative Institute for Research in Environmental \\ Sciences, University of Colorado, Boulder, Colorado \\ K. KRISHNA KUMAR \\ Cooperative Institute for Research in Environmental Sciences, University of Colorado, Boulder, Colorado, and Indian Institute of \\ Tropical Meteorology, Pune, India \\ MARTYN CLARK \\ Cooperative Institute for Research in Environmental Sciences, University of Colorado, Boulder, Colorado
}

(Manuscript received 10 December 2003, in final form 9 November 2004)

\begin{abstract}
Summer monsoon rains are a critical factor in Thailand's water resources and agricultural planning and management. In fact, they have a significant impact on the country's economic health. Consequently, understanding the variability of the summer monsoon rains over Thailand is important for instituting effective mitigating strategies against extreme rainfall fluctuations. To this end, the authors systematically investigated the relationships between summer monsoon precipitation from the central and northern regions of Thailand and large-scale climate features. It was found that Pacific sea surface temperatures (SSTs), in particular, El Niño-Southern Oscillation (ENSO), have a negative relationship with the summer monsoon rainfall over Thailand in recent decades. However, the relationship between summer rainfall and ENSO was weak prior to 1980. It is hypothesized that the ENSO teleconnection depends on the SST configuration in the tropical Pacific Ocean, that is, an eastern Pacific-based El Niño pattern, such as is the case in most of the post-1980 El Niño events, tends to place the descending limb of the Walker circulation over the Thailand-Indonesian region, thereby significantly reducing convection and consequently, rainfall over Thailand. It is believed that this recent shift in the Walker circulation is instrumental for the nonstationarity in ENSO-monsoon relationships in Thailand. El Niños of 1997 and 2002 corroborate this hypothesis. This has implications for monsoon rainfall forecasting and, consequently, for resources planning and management.
\end{abstract}

\section{Introduction and background}

El Niño-Southern Oscillation (ENSO) has been widely known to modulate the Asian summer monsoons on interannual and interdecadal time scales.

Corresponding author address: Balaji Rajagopalan, Dept. of Civil, Environmental and Architectural Engineering, University of Colorado, ECOT-541, Campus Box 428, Boulder, CO 803090428.

E-mail: balajir@colorado.edu
Some examples include relationships between ENSO and the Indian monsoon (Krishna Kumar et al. 1999; Krishnamurthy and Goswami 2000), and between ENSO and the South China monsoon (Xu and Chan 2001; Lau and Wu 2001; Wang et al. 2001). ENSO also affects the onset of the monsoons (e.g., Indonesian rainfall; Hamada et al. 2002). In general, most previous studies suggest that a reduction in the strength of monsoons in these regions with El Niño and vice versa (Rasmusson and Carpenter 1983; Rupakumar and Pant 1997) was largely caused by shifts in the Walker circu- 
lation. Furthermore, this dynamical relationship has been extensively used for issuing the seasonal forecast of monsoons, in particular the Indian summer monsoon (Shukla and Paolino 1983; Krishna Kumar et al. 1995). Land surface processes such as variability in continental heating associated with snow cover and vegetation structure can also play a significant role in modulating the land-ocean gradients and consequently, impacting the strength of the monsoons and also the ENSO teleconnections (Blanford 1884; Bamzai and Shukla 1999; Chase et al. 1996, 2000; Krishna Kumar et al. 1999).

Interestingly, in recent decades there has been a weakening of the relationship between ENSO and Indian summer monsoon rainfall (Krishna Kumar et al. 1999), including the East Asian summer monsoon (Chen et al. 2002). On the other hand, Wang et al. (2001) find a steady relationship between ENSO and the western North Pacific summer monsoon. Such nonstationarity in the large-scale relationship may indicate a wider readjustment of tropical atmospheric circulation with potential impacts on other monsoons in the region. Monsoon variability over Thailand has not been studied as widely as its counterparts in the Indian subcontinent and China. There have been some efforts to understand the relationship between rainfall over Thailand, Singapore, and Indonesia with Indian rainfall based on $20 \mathrm{yr}$ of data before 1980 (1961-80) by Kripalani and Kulkarni (1997, 1998, 2001). In general, these investigations depicted a weak relationship between the summer rainfall over Thailand and Indian rainfall.

Past research, as mentioned above, has focused on several regions in Asia, but there are hardly any studies investigating the variability of Thailand's hydroclimate. Our research systematically investigates the temporal variability of Thailand hydroclimatology; in particular, the summer monsoon. The paper is organized as follows: datasets and Thailand climatology are first described; trends in precipitation, temperature, and streamflow are then presented; and understanding the temporal variability and a proposal of potential physical mechanisms concludes the paper.

\section{Data}

\section{a. Hydroclimate data}

The central region of Thailand is the most important area for Thailand's economy. This region produces huge quantities of agricultural products for both domestic consumption and export. The Chao Phraya River passing through this central region is a key factor for the agricultural production and other economic activities. Therefore, hydroclimate data from this region

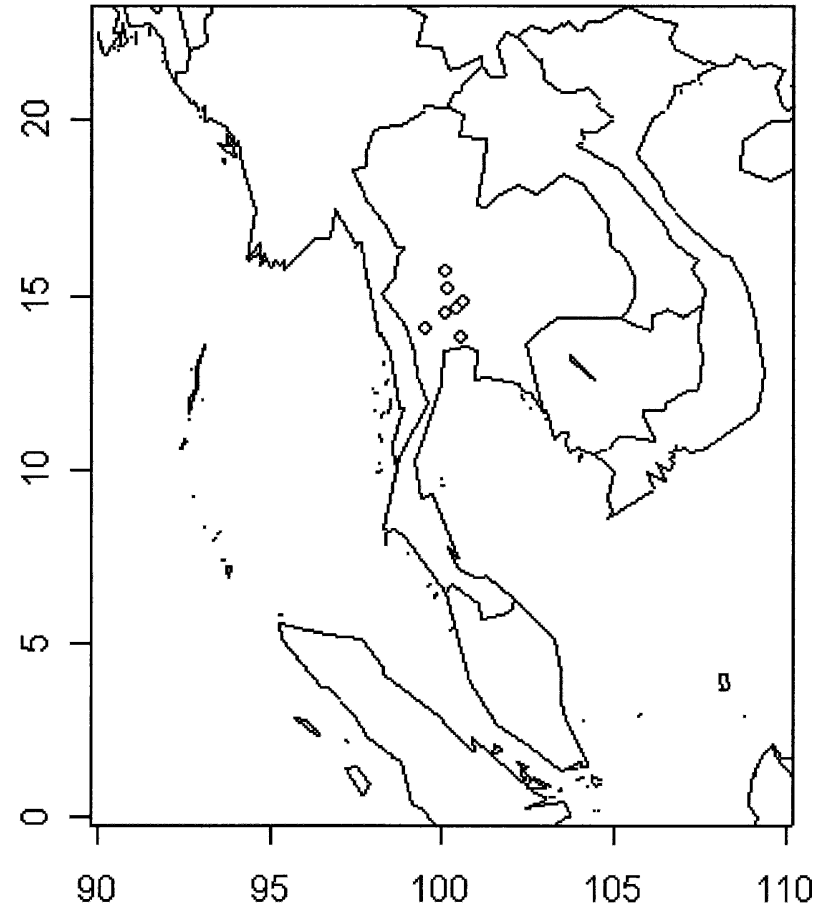

FIG. 1. Map of Thailand and surroundings with the location of hydroclimate data stations shown as points.

have been selected for this study. Long records of precipitation, temperature, and streamflow were obtained from the Global Energy and Water Cycle Experiment (GEWEX) Asian Monsoon Experiment (GAME) project Web site (see online at http://hydro. iis.u-tokyo.ac.jp/GAME-T/GAIN-T/routine/rid-river/ longterm.html), the Thailand Meteorological Department, and the Royal Irrigation Department. The GAME program has done a good job of collecting and archiving data from Southeast Asian countries. Although data are available from these sources, they are sparse and in general, it has been difficult obtaining long hydroclimate data from Thailand.

Daily precipitation and temperature data have been obtained from six locations in the central Thailand region for the 1951-2001 period (shown as points in Fig. 1). The stations are Nakhon Sawan (Nk), located in the northernmost province of central region and the origin of Chao Phraya River; Suphan Buri (Sp), in the central region; Lop Buri (Lp), located near the northern boundary of the central region; Kanchana Buri (Kn), located near the western boundary of the central region; Bangkok (Bkk), the capital of Thailand, located near the mouth of the Chao Phraya River; Don Muang (Dm), a city in Bangkok and location of the biggest international airport in Thailand. Daily streamflow data at three stations along the Chao Phraya River were also obtained. The stations are $\mathrm{Nk}$, drainage area 
about $110569 \mathrm{~km}^{2}$ (1956-2000); Chai Nat (Cn), a province adjacent to Nakhon Sawan, drainage area about $120693 \mathrm{~km}^{2}$ (1948-2000); and Ang-Thong (At), a province near Bangkok (1976-96).

To check for consistency, annual values of precipitation, streamflow, and temperature at the stations were correlated among themselves; that is, for each variable, the data from a station are correlated with data from all other stations. The data at the stations are generally well correlated (average correlation ranges from 0.5 to $\sim 0.9$ ), with streamflows and temperatures exhibiting stronger correlations than precipitation. This is to be expected, as the time series of rainfall is more variable than the temperature and streamflow time series. Overall, these interstation correlations suggest that the hydroclimate is fairly homogeneous. Similar correlations were found for the monsoon season. Consequently, we averaged the data over selected representative stations that exhibited good interstation correlations for precipitation, temperature, and streamflow to develop "index" time series. For rainfall, we selected, Nk, Sp, and Dm stations; for temperature, we used all the five stations; and for flows, station Cn was used. Almost all the stations are from west-central Thailand (see Fig. 1), which is the core region of the Chao Phraya River basin-the "life blood" of Thailand's socioeconomic well being. Hence, these average index time series are referred to as Thailand precipitation, streamflow, and temperature, respectively.

The streamflow data that we obtained are at reservoir locations and as such, appear to be highly regulated. In light of this we restrict the analysis of streamflow data to long-term trends only.

\section{b. Large-scale climate data}

Large-scale ocean and atmospheric circulation variables such as sea level pressure (SLP), sea surface temperature (SST), and velocity potential were obtained from the National Centers for Environmental Prediction-National Center for Atmospheric Research (NCEP-NCAR) reanalysis (Kalnay et al. 1996). The SST data are from Kaplan et al. (1998) obtained from a "reduced space" optimal smoother algorithm applied to $131 \mathrm{yr}$ (1865-1995) of global SST monthly anomalies obtained from the U.K. Hadley Center archives (Bottomley et al. 1990). (These data and ENSO indices spanning the period of 1948-present are available online at http://www.cdc.noaa.gov.)

\section{Climate diagnostics}

In this section climatology and long-term trends in the hydrometeorological variables such as precipita- tion, surface air temperature, and streamflow are first analyzed. Investigations into the links between largescale ocean-atmospheric circulation features and interannual and decadal variability in the summer monsoon rainfall are then presented. Correlation and composite analyses are used for the diagnostics.

First, we check the temporal consistency of the developed precipitation and temperature time series. Thailand precipitation during the monsoon season (August-October) and premonsoon spring seasonal (March-May) temperatures were correlated with gridded Climate Prediction Center (CPC) Merged Analysis of Precipitation (CMAP) global rainfall data (Xie and Arkin 1997) and NCEP-NCAR reanalysis (Kalnay et al. 1996) surface temperature data, respectively, shown in Figs. 2a,b. It can be seen that a strong positive correlation exists over Thailand, in particular, over the west-central part of the country, from where the rainfall and temperature data are obtained. This indicates that the hydroclimate data obtained above can be considered to be fairly representative of the country and certainly the important region of west-central Thailand.

\section{a. Hydroclimatology}

The climatological annual cycle of Thailand temperature, rainfall, and streamflow are shown in Fig. 3. It can be seen that the "hottest" season in Thailand is the Northern Hemisphere spring season (Fig. 3a), MarchApril-May (MAM), which is also the premonsoon season. Precipitation peaks during August-SeptemberOctober (ASO; Fig. 3b). In addition, May shows a secondary maximum that occurs consistently over all the stations. This secondary peak is associated with the northward movement of the intertropical convergence zone (ITCZ). The southwest monsoon that starts during May in the Indian Ocean brings warm, moist airstreams passing from the Indian Ocean toward Thailand in May, causing thunderstorms during this period. The ITCZ covers the southern part of Thailand in May as well; however, it moves to the South China Sea in mid-May and then southern China and central China in late May and mid-June, respectively. In August the ITCZ moves southward and lies over northern and northeastern Thailand, and then over central regions in September and southern parts in October, thus, causing the primary peak in seasonal rainfall (i.e., the monsoon season) to be during ASO. Henceforth, we refer to monsoon rainfall as the total rainfall during ASO and the premonsoon temperature as the average temperature during MAM. For streamflow (Fig. 3c), it is apparent that the annual peak occurs during SeptemberOctober-November (SON), lagging a month behind 


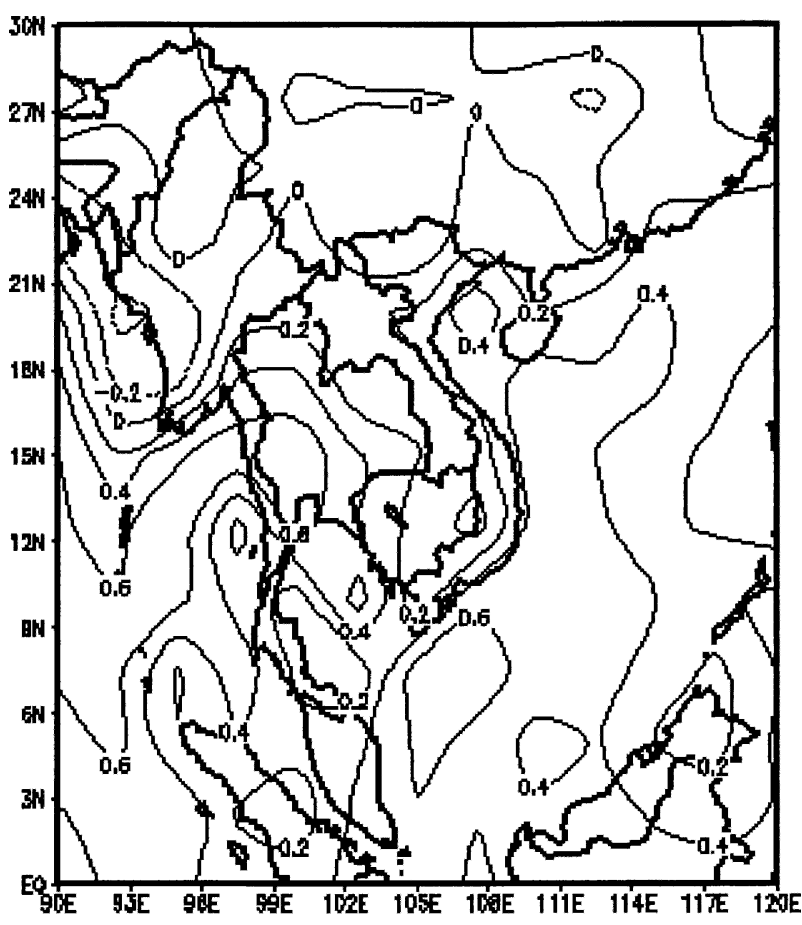

(a)

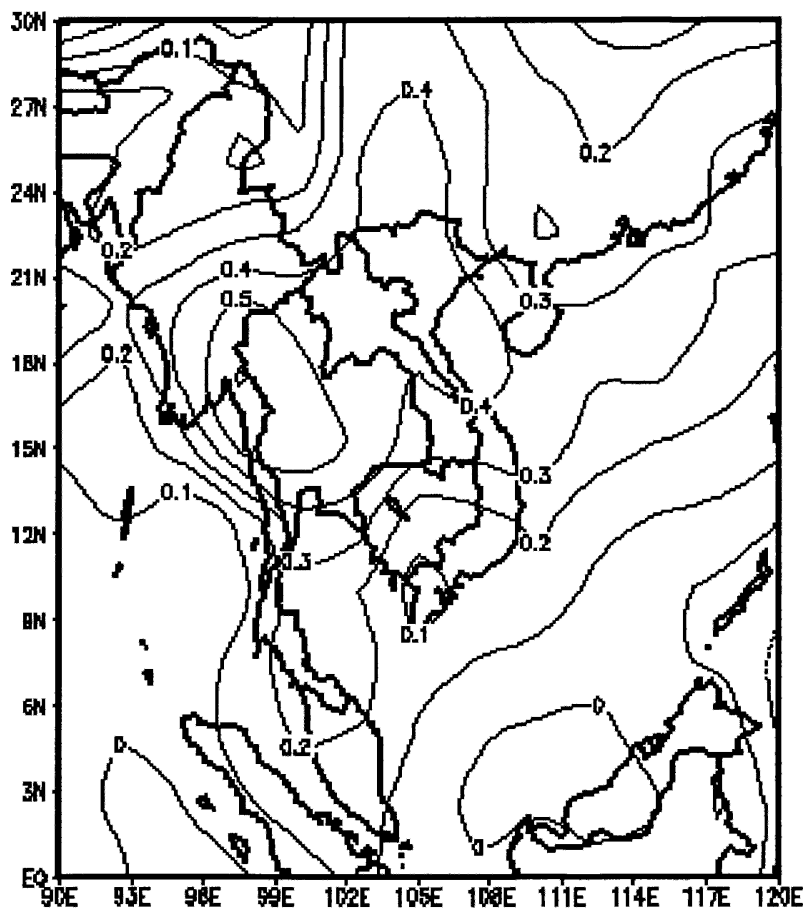

(b)

FIG. 2. Correlation between (a) Thailand summer rainfall and CMAP rainfall during monsoon season (ASO) and (b) Thailand temperature and reanalysis surface temperatures during premonsoon spring season (MAM). The $95 \%$ significance levels are \pm 0.21 . the rainy season. Large flows are frequently found in October.

The premonsoon air temperatures over the land play a key role in setting up the land-ocean gradient, which is important to the strength of the monsoon rainfall. The enhanced land-ocean gradient leads to a stronger monsoon and vice versa. These links can be corroborated in Fig. 4. Figure 4a shows the scatterplot of surface temperatures over Thailand during the premonsoon season with the monsoon seasonal rainfall. A linear relationship (statistically significant at the $95 \%$ confidence level) can be seen, indicating that higher temperatures during spring tend to favor a stronger monsoon. Mean surface temperatures over the entire premonsoon period (i.e., March-July) also exhibit similar linear relationship with the monsoon rainfall (figure not shown). Premonsoon land temperatures are generally thought to be associated with developing the landocean contrast, a key ingredient for the summer monsoon (e.g., Webster et al. 1998; Krishna Kumar et al. 1999; Liu and Yanai 2001). However, the land region and the season that is responsible for setting up of the land-sea gradient is not fully understood so we urge caution in interpreting Fig. 4a.

Figure $4 \mathrm{~b}$ shows the scatterplot of rainfall and temperature during the monsoon season. As expected, an inverse relationship is apparent (though not statistically significant), that is, enhanced seasonal rainfall tends to cool the land and the atmosphere, thereby, decreasing the temperatures and vise versa. One reason for this weak inverse relationship is that the monsoon seasonal temperature exhibits an increasing trend, especially in the post-1970 period (figure not shown) and corroborated in Adger et al. (2001). This increasing trend counters the inverse relationship and consequently, a weak correlation. These figures confirm the physical consistency between the hydroclimate variables, thus, enhancing the confidence in the datasets.

\section{b. Time series trends}

To investigate the temporal variability and the longterm trends of the hydroclimate variables, linear trends were computed. Figures 5a,b shows the standardized anomaly time series of spring temperatures and monsoon rainfall. Interestingly, both these series exhibit a strong decreasing (negative) trend over the 50-yr period. They are consistent in that, decreasing spring temperatures lead to decreasing monsoon rainfall. Linear regression fits to the data show a temperature trend of $-0.4^{\circ} \mathrm{C}$ and $-180 \mathrm{~mm}$ trend in precipitation over $50 \mathrm{yr}$. These trends are found to be statistically significant at the $90 \%$ confidence level when tested using the standard $t$ test (Helsel and Hirsch 1995). Also note that the 
(a)

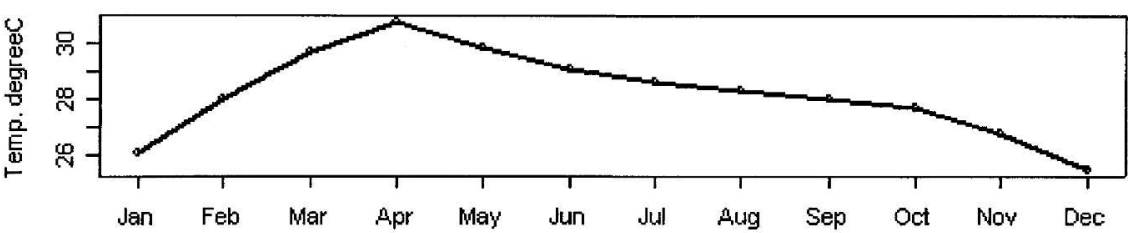

(b)

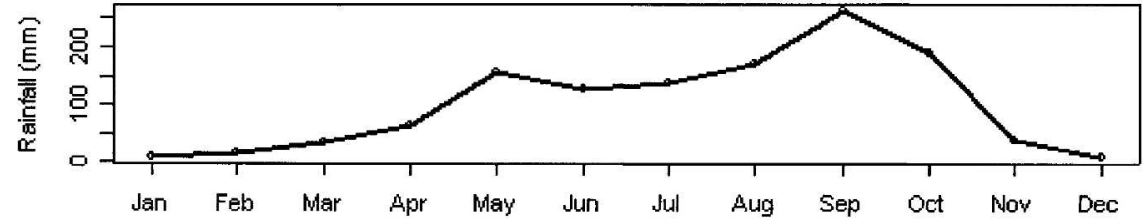

(c)

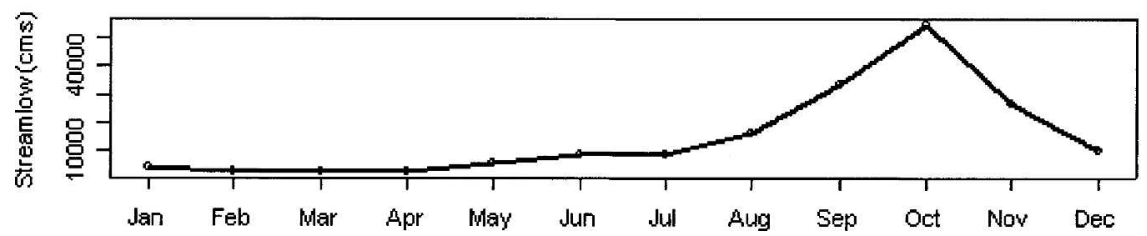

FIG. 3. Annual cycle of Thailand's (a) temperature, (b) rainfall, and (c) streamflow.

El Niño and La Niña years seem to generally correspond with low and high rainfall years (Fig. 5b), respectively, in the recent decades. Time series of monsoon seasonal temperature and seasonal streamflow are shown in Figs. 5c,d, respectively. An increasing trend in monsoon seasonal temperatures can be seen. This is consistent in that, decreasing rainfall trends (Fig. 5b) tend to result in reduced cooling of the land and atmo- sphere, thereby, increasing the temperatures (Fig. 5c). Decreasing seasonal streamflows (Fig. 5d) are also consistent with the negative trend in rainfall. While general trends are apparent in these figures, decadal trends can also be seen. To elucidate this, local polynomial fits (Loader 1999) are shown as solid lines in Fig. 5. Local polynomial method is a nonparametric approach that has the ability to capture any arbitrary relationship (i.e., (a)

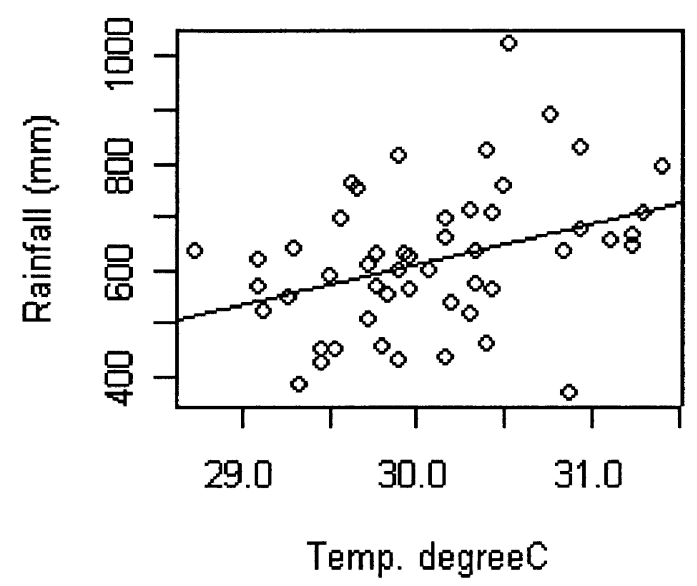

(b)

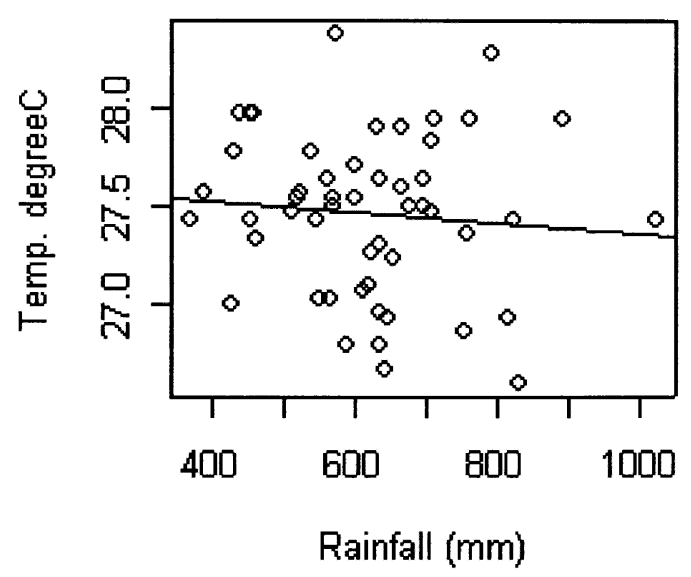

FIG. 4. Scatterplot of (a) premonsoon MAM mean temperature and ASO rainfall and (b) ASO rainfall and temperature. Linear regression fits are shown as solid line. 
(a)

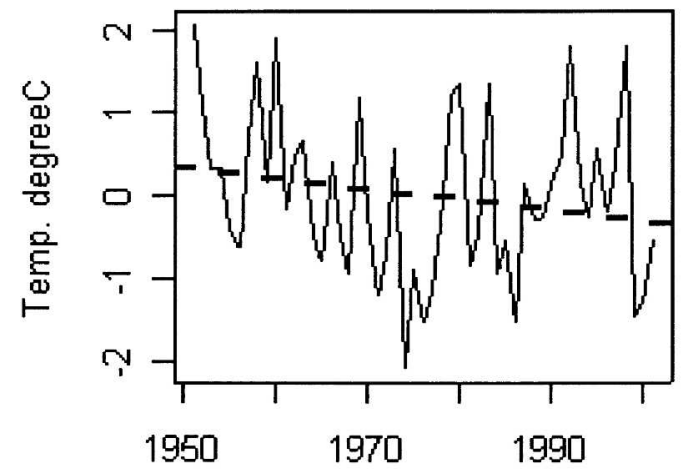

(c)

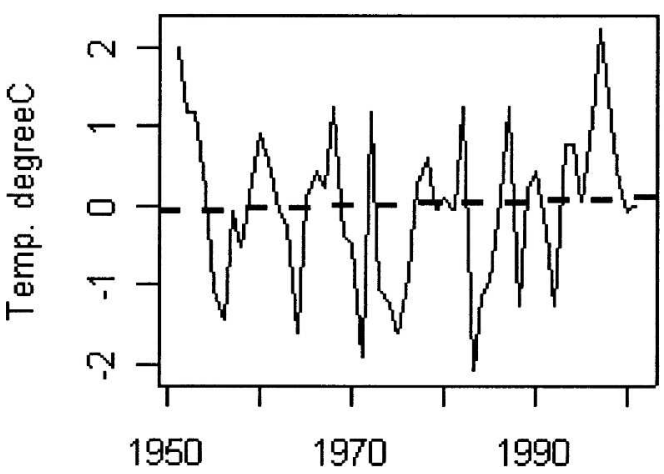

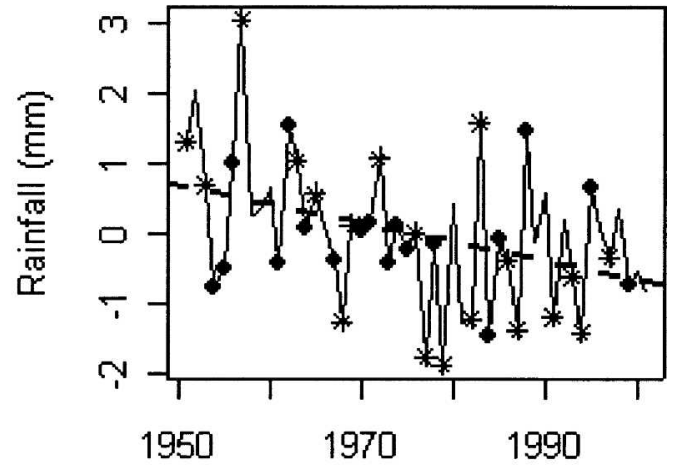

(d)

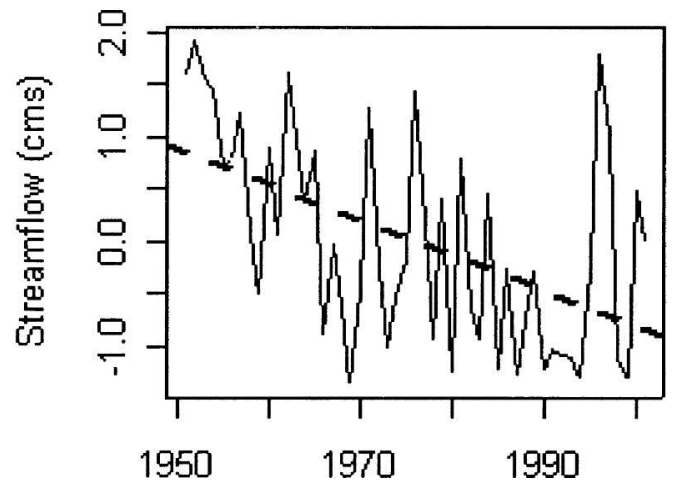

FIG. 5. Standardized anomaly time series plot of (a) MAM temperature, (b) ASO rainfall, (c) ASO temperature, and (d) SON streamflow. Dashed lines are linear regression fits to the data and solid lines represent the local polynomial fits. El Niño and La Niña years are shown as asterisks and dots, respectively, in (b).

linear or nonlinear) exhibited by the data without a priori assumptions as to the form of the variability, as in the case of linear regression. Adger et al. (2001) reports a warming trend over Thailand in the spring temperatures during 1976-99. In fact, a warming trend can be seen from 1980 to the present in Fig. 5a; however, the overall trend from 1950 is a decreasing one. Adger et al. (2001) also shows a decreasing trend in precipitation over Thailand consistent with Fig. 5b. In summary, the trends in temperature and precipitation seen here are consistent with those reported in Adger et al. (2001) the reversal in precipitation trends in the late 1970s should be kept in mind for the discussion in the following sections. Significant interannual and interdecadal variability is also seen in these variables.

\section{c. Relationship to ENSO}

While the long-term trends in temperature and precipitation may be linked to global trends, it is important to understand the interannual and interdecadal varia- tions. As Thailand is close to the equatorial IndoPacific basins, the first step is to investigate the relationships with ENSO. To this end, 21-yr moving window correlations between Thailand monsoon rainfall and the Southern Oscillation index (SOI), a sea level pressure-based ENSO index, are plotted in Fig. 6 (solid line). Significant correlations are seen after 1980. Prior to 1980 there is hardly any relationship.

To further understand this relationship, the monsoon rainfall is correlated with large-scale ocean-atmospheric circulation variables for the pre- and post-1980 periods. Figure 7 (top and middle panels) shows the correlation between monsoon rainfall and SSTs and SLPs for the two periods. The pre-1980 period shows very weak correlations in the tropical Pacific region-in fact, a small region of positive correlation in the eastern tropical Pacific can be seen. But in the post-1980 period, a negative correlation is seen in the central to eastern Pacific and positive correlations are evident in the western Pacific, which is reminiscent of the ENSO pattern. Similar observations can be found with SLPs 


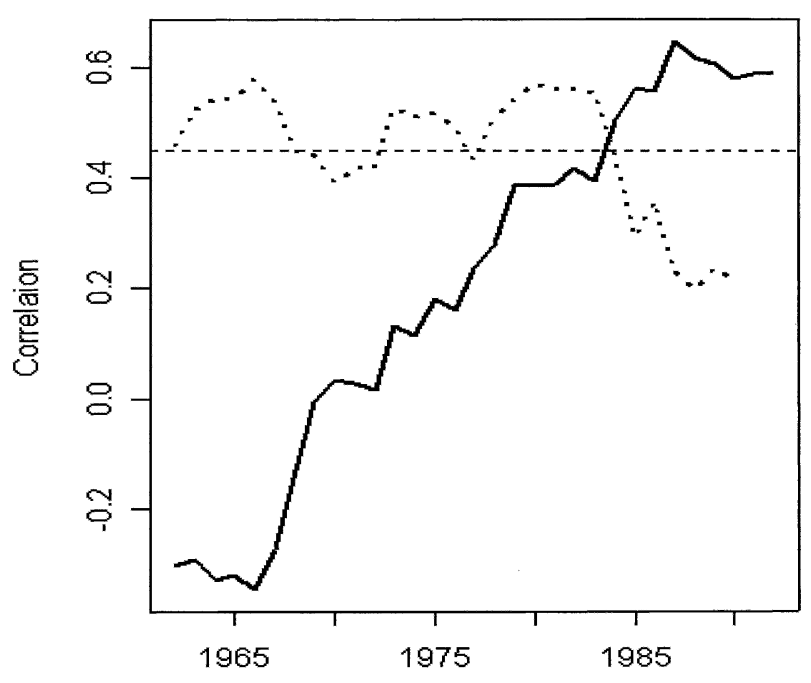

FIG. 6. The 21-yr moving window correlation between the Thailand monsoon (ASO) rainfall and (ASO) the SOI index (solid line); and between the Indian summer monsoon (JJAS) and (JJAS) the SOI (dotted line). The dashed line at 0.45 is the $95 \%$ significance level.
(Fig. 7, middle panel); in fact, the pattern resembling the Southern Oscillation is much stronger in SLP. To examine relationships with the Walker circulation, correlations between monsoon rainfall and velocity potential at $200 \mathrm{hPa}$ (a surrogate for Walker circulation) were computed for the pre- and post-1980 periods (Fig. 7, bottom panel). It can be seen that the correlations are significant in the post-1980 period resembling the SLP correlations (Fig. 7, middle panel) and are dynamically consistent over Thailand, that is, enhanced subsidence and reduced rainfall (negative correlation over Thailand). Interestingly, the pattern seen in Fig. 7(bottom panel) for the post-1980 period is very similar to the correlation between Indian monsoon and velocity potential at $200 \mathrm{hPa}$ during pre-1980 period reported by Krishna Kumar et al. (1999, see their Fig. 2).

To further confirm the results in Fig. 7, we checked for significance of the ASO mean SST difference between wet and dry years in the two periods. Data in the top and bottom 15th percentile are listed as being wet (high) and dry (low) rainfall years (see Table 1).


FIG. 7. Correlation between ASO rainfall and (top) ASO SST, (middle) ASO SLP, and (bottom) velocity potential at $200 \mathrm{hPa}$, for the pre- and post-1980 periods. The $95 \%$ significance levels are \pm 0.45 . 
TABLE 1. List of the three highest and lowest rainfall years during pre- and post-1980.

\begin{tabular}{lcc}
\hline \hline & Pre-1980 & Post-1980 \\
\hline High years & $1952,1957,1962$ & $1983,1988,1995$ \\
Low years & $1968,1977,1979$ & $1984,1987,1994$ \\
\hline
\end{tabular}

Figure 8 shows the monsoon season composite mean SST difference between high and low rainfall years for the two periods. Regions with significant differences in mean SST at the $90 \%$ confidence levels on a traditional $t$ test (Helsel and Hirsch 1995) are shaded and the mean SST differences are shown as contours. It can be seen that during the post-1980 period high (low) years tend to go with significant cooling (warming) in the tropical Pacific region well to the east of date line-this is a clear ENSO pattern. In the pre-1980 period, this pattern is largely absent, thus, supporting the correlation plots in Fig. 7. These results are suggestive and should be viewed with caution because of the small sample size.

Spectral analysis of rainfall shows a significant band around $2.5 \mathrm{yr}$ and a trend (Fig. 9a). A moving window spectral coherence of the monsoon rainfall (Fig. 9b) and SOI shows significant power in the $2.5-3$-yr band in recent decades. These results are based on the multitaper method (MTM) of spectral analysis (Thomson 1982; Mann and Lees 1996). The MTM is a nonparametric spectral analysis method that has been shown to perform much better than traditional spectral methods. (The MTM codes can be obtained online at http:// holocene.evsc.virginia.edu/Mann/tools/tools.html.) The spectral results further corroborate the recent ENSO connection to Thailand rainfall.

\section{The physical mechanism}

The interesting question is why does ENSO modulate Thailand rainfall in recent decades? Is there a change in the ENSO pattern in recent decades? If so, does this have regional impacts? What could be the physical mechanism?

To answer these, composites of ASO mean SST differences between El Niño years in the pre-1980 (1957, $1965,1972)$ and post-1980 (1982, 1987, 1997, 2002) period were made and shown in Fig. 10. Notice significantly warmer SST anomalies (shaded regions in the

(a)



(b)

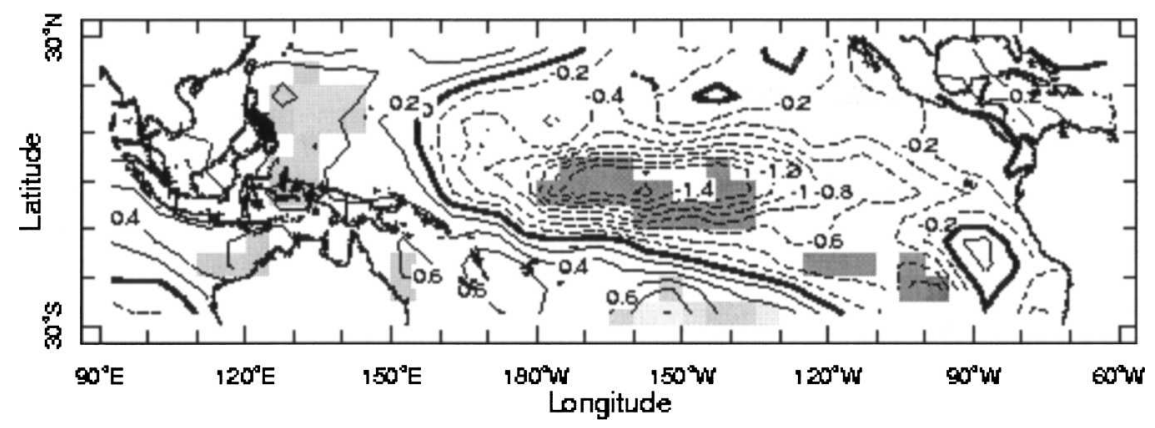

FIG. 8. Composite maps of mean ASO SST $\left({ }^{\circ} \mathrm{C}\right)$ anomaly differences between high rainfall and low rainfall years during (a) pre-1980 and (b) post-1980. Shaded regions are significant at the $90 \%$ confidence level on a standard $t$ test. 
(a)

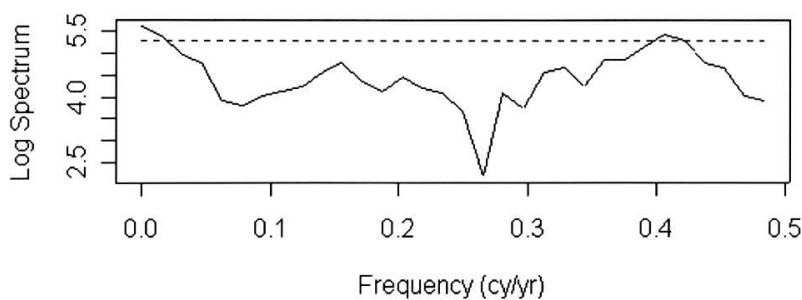

(b)

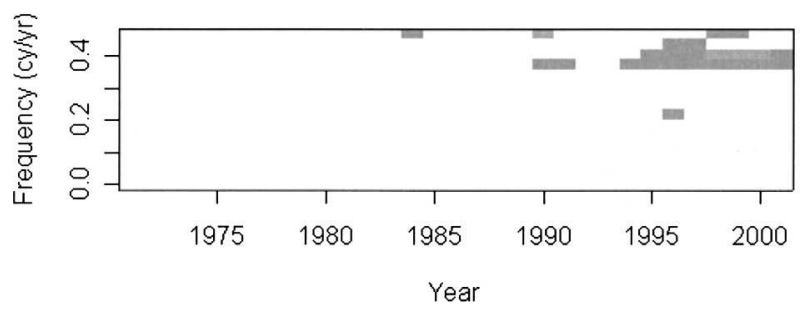

FIG. 9. (a) Spectrum of Thailand monsoon rainfall (dashed line is the $95 \%$ significance level) and (b) 21-yr moving window spectral coherence between Thailand monsoon rainfall and the ASO SOI. Shaded regions are significant at the $95 \%$ confidence level.

figure) to the east of the date line in the tropical Pacific in the El Niño events of the recent period relative to the earlier period. To examine if this has an impact on the atmospheric circulation (i.e., the Walker cell), the same was done on the velocity potential fields for the preand post-1980 El Niño events (Fig. 11). Strengthening of the velocity potential (i.e., positive anomalies) during recent El Niño events relative to the earlier period, over a large region extending from the Indian subcontinent to Australia can be seen. Furthermore, there is a southastward shift (shaded region in the figure) of the descending limb of the Walker cell over to Thailand in the recent decades, consistent with the shifts in the SST patterns. The pattern seen in Fig. 11 is similar to the southeastward shift in Walker circulation anomalies identified by Krishna Kumar et al. (1999, see their Fig. 2). The ENSO-related SST shifts and the associated shifts in Walker circulation and correlations between Thailand rainfall and Walker circulation all appear to be consistent. Clearly, these shifts will have implications to the Indian monsoon and Thailand monsoon in terms of their relationship to ENSO. This is clearly seen in Fig. 6 (dotted line), which shows the moving window correlation between Indian and Thailand monsoons with SOI. Around 1980, the Indian monsoon starts to lose its correlation with ENSO while the Thailand monsoon picks up correlation.

The hypothesis proposed by Krishna Kumar et al. (1999) in the context of the Indian monsoon seems to be responsible for the shifting correlations as seen in Fig. 6. The hypothesis is as follows: the eastern Pacificcentered ENSOs tend to constrain the descending branch of the Walker circulation within the Pacific domain, thereby, reducing convection in the tropical western Pacific regions and consequently, impacting the rainfall in these regions (including the Thailand monsoon). Under this situation, the Indian subcontinent is not directly influenced by ENSO, and land surface processes (e.g., snow cover) are the dominant driving force for monsoonal variability. On the other hand, if the ENSOs are date line centered then the descending branch of the Walker circulation has a wider reach over the Indian subcontinent, which decreases convection, and the Indian monsoon gets impacted much more than the Thailand monsoon.

Interestingly, this hypothesis is corroborated during the El Niños of 1997 and 2002. Figure 12a shows the composite seasonal (June-October) SSTs and precipitation for 1997 and Fig. 12b for 2002. It can be seen that in 1997, the year of the strongest El Niño in recorded history, the SST pattern shows a strong warming in the eastern Pacific, and the rainfall over Thailand shows a deficit while over the Indian subcontinent it is close to

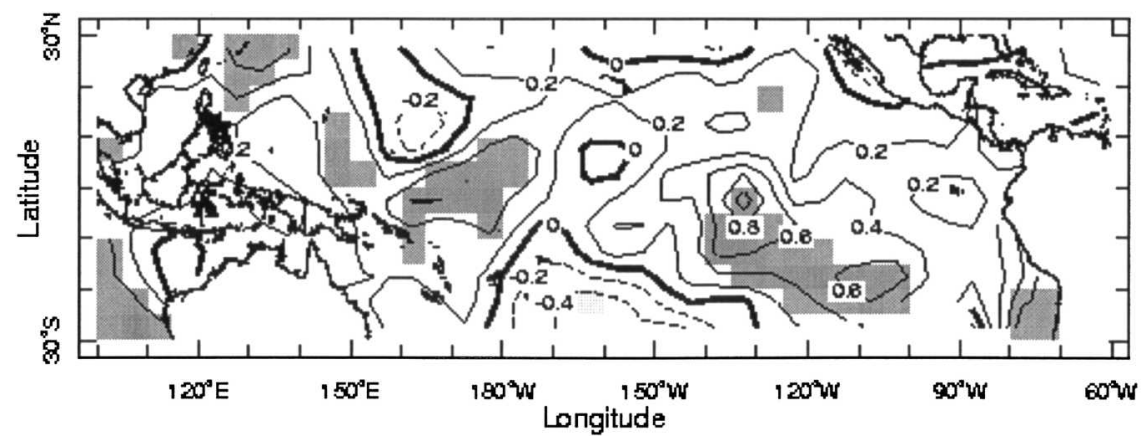

FIG. 10. Composite map of mean ASO SST $\left({ }^{\circ} \mathrm{C}\right)$ anomaly differences between El Niño years in post-1980 and pre-1980 periods. Shaded regions are significant at the $90 \%$ confidence level on a standard $t$ test. 


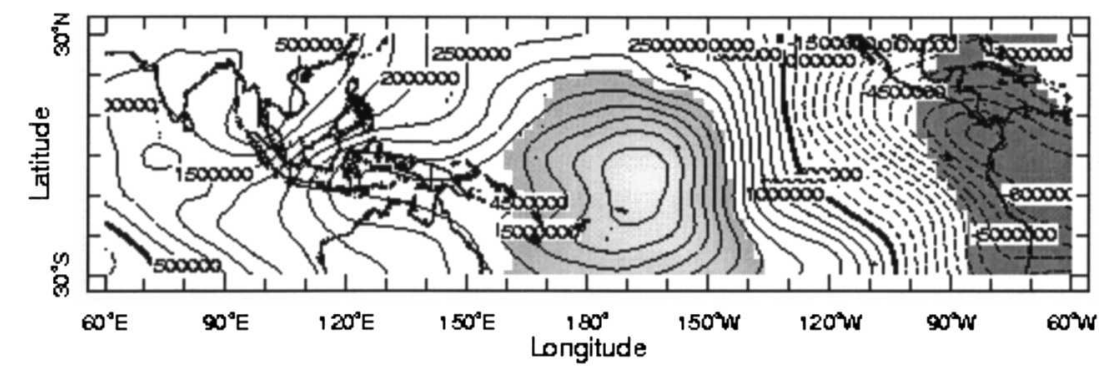

$200 \mathrm{mb}$

FIG. 11. Same as Fig. 10 but for mean ASO velocity potential at $200 \mathrm{hPa}$.

normal. In 2002 (Fig. 12b), on the other hand, El Niño was weaker in comparison but with stronger warming around the date line region, produced normal to abovenormal rainfall over Thailand and a substantial deficit over India. Climate model experiments have to be performed to further understand this hypothesis.
Given the climatologically colder SSTs in the eastern Pacific Ocean, it is likely that strong SST anomalies in the eastern Pacific are necessary to force an eastward shift in tropical convection and in the Walker circulation. Such strong SST anomalies did in fact occur during the 1982/83 and 1997/98 El Niño events. The rela-

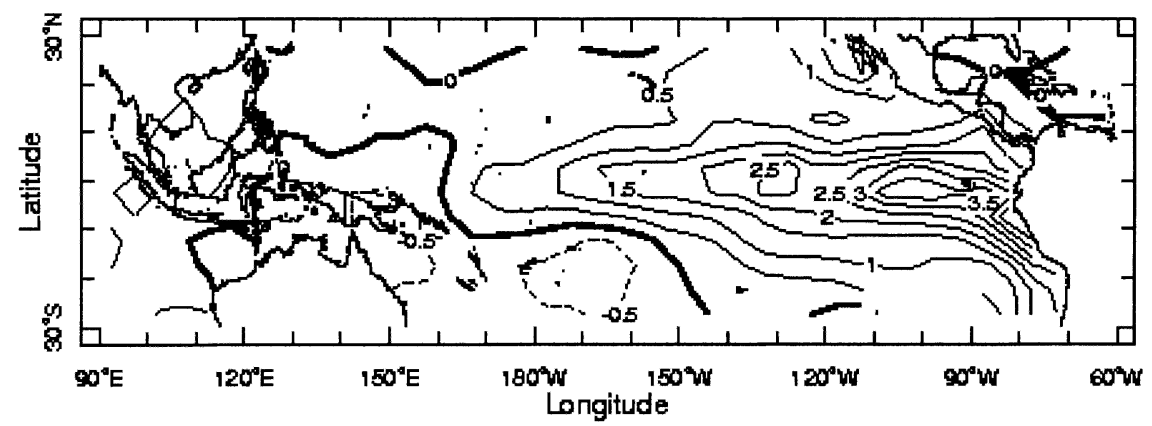

SST

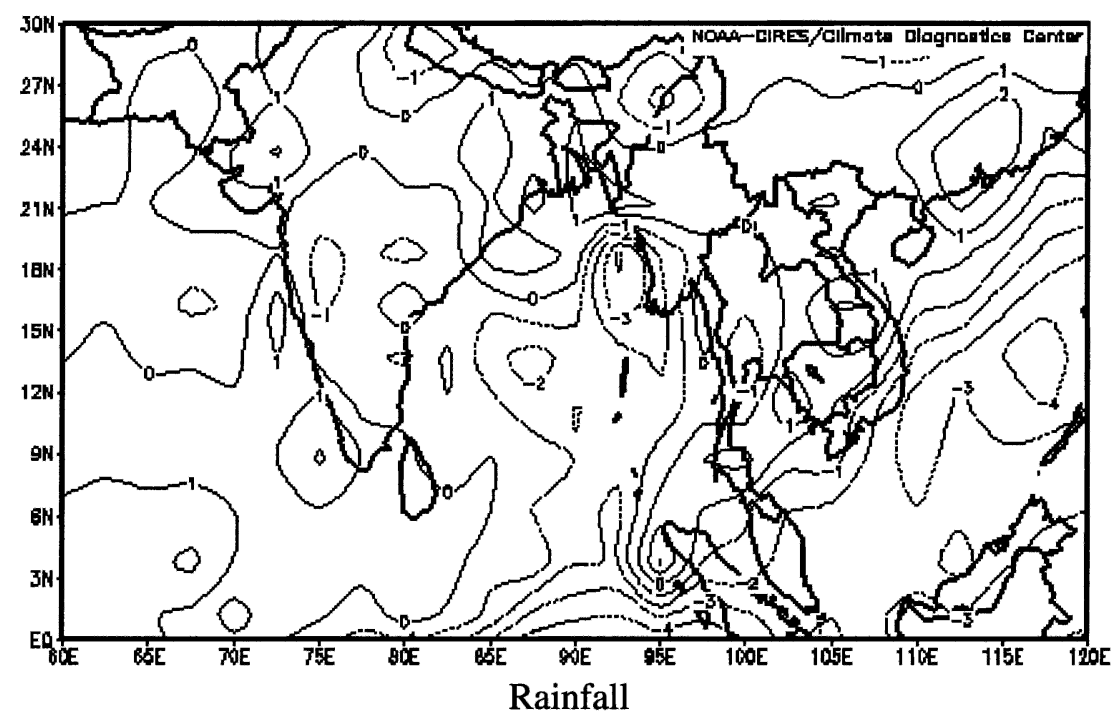

(a)

FIG. 12. Composite maps of SST $\left({ }^{\circ} \mathrm{C}\right)$ and Jun-Oct rainfall $\left(\mathrm{mm} \mathrm{day}^{-1}\right)$ anomalies for the (a) 1997 and (b) 2002 El Niño events. 

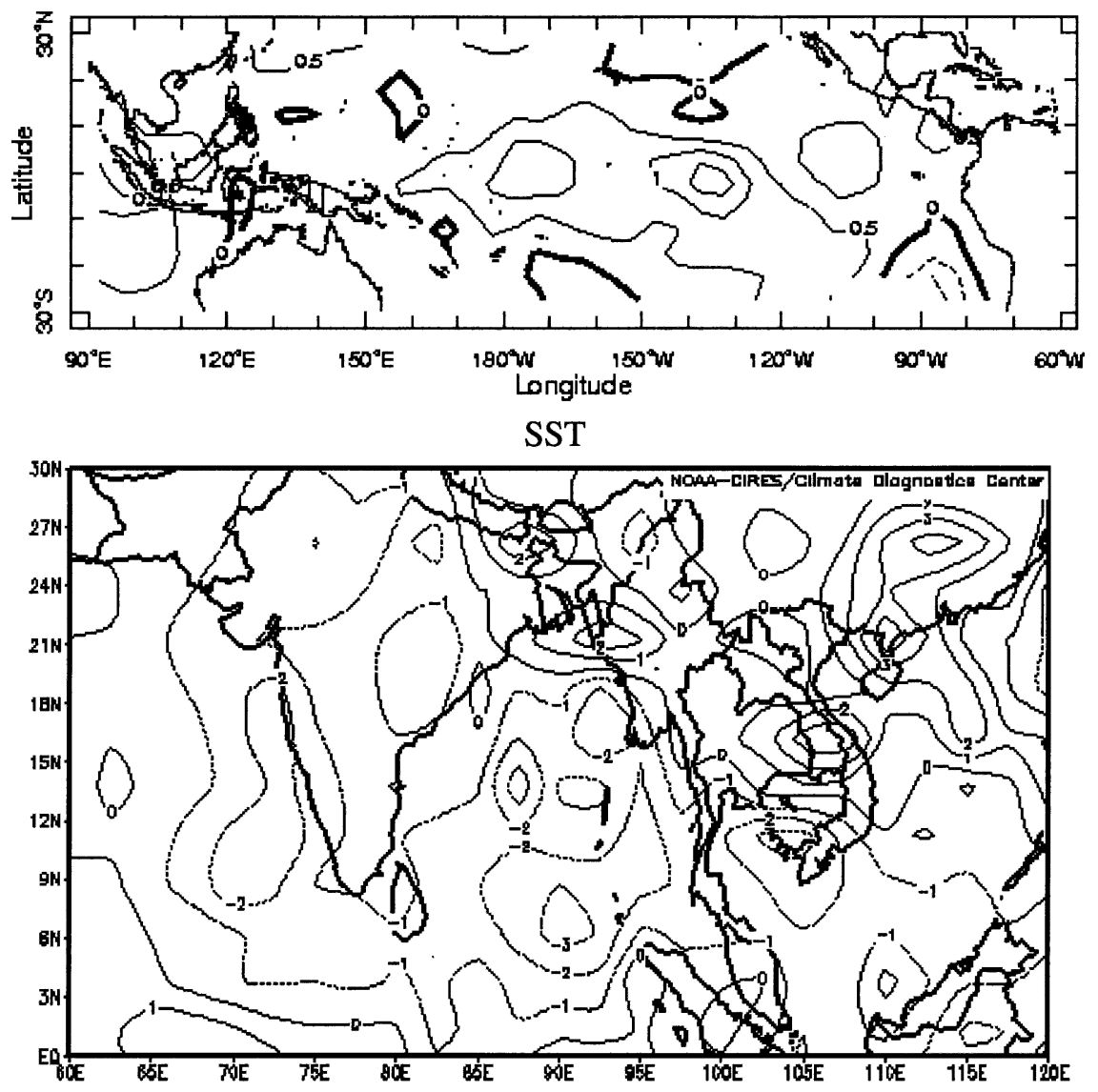

Rainfall

(b)

FIG. 12. (Continued)

tive importance of the longitudinal position of SST anomalies and the strength of SST anomalies is difficult to ascertain in observational studies, but this knowledge is critical for improved seasonal forecasts of monsoon precipitation. Further research is warranted on this topic.

\section{Summary}

Thailand hydroclimatology exhibits a strong trend and interdecadal variability. The variability in recent decades (post-1980) seems to be strongly linked with ENSO. Interestingly, during the same period, the Indian monsoon shows a weakening in its relationship with ENSO. These findings seem to argue for a tropical-wide ENSO-related circulation shifts with more eastern Pacific-centered ENSOs in recent decades.

We are cautious that the atmospheric circulation changes in the NCEP-NCAR reanalysis data for the pre- and post-1970 period presented here (i.e., when satellite data were ingested in the analysis) may not agree with observations (see, e.g., Trenberth et al. 2001; Wu and Xie 2003; Kinter et al. 2004). However, our results are corroborated with independent information; for example, in Fig. 6 we show moving window correlations between the Thailand monsoon rainfall and SOI, and this clearly shows significant correlations in the post-1980 period. Furthermore, the significant results are in the post-1980 period during which the reanalysis data is much more reliable.

The dominant mechanism to impact rainfall over Thailand seems to be via the Walker circulation. Eastern Pacific-centered ENSOs tend to largely contain the descending branch of the Walker circulation within the Pacific domain, while the descending branch from date line-centered ENSOs tend to extend strongly over the Indian subcontinent. Two recent years, 1997 and 2002 clearly corroborate this hypothesis. The tantalizing question of what causes the shifts in ENSO-related SST patterns in the equatorial Pacific remains. Perhaps, it 
could be a result of enhanced midlatitude warming as Krishna Kumar et al. (1999) suggest, or it could be natural variability of the tropical Pacific system (Wang et al. 2001). This needs further investigations using model experiments and data.

Acknowledgments. The authors thank Somkiat Apipattanavis and Tom Chase for useful discussions. The first author is grateful to the Thailand government for the graduate student fellowship and to the Thailand Public Works Department for their encouragement and support. Travel support from IUGG to the first author to present preliminary results from this work at the IUGG General Assembly 2003 in Sapporo, Japan, is very much appreciated. Funding for the third author via CIRES Visiting Fellowship is also gratefully acknowledged. Finally, the authors want to thank two anonymous reviewers whose comments greatly improved the manuscript.

\section{REFERENCES}

Adger, W. N., and Coauthors, 2001: Asia. Climate Change 2001: Impacts, Adaptation and Vulnerability, J. J. McCarthy et al., Eds., Cambridge University Press, 535-581.

Bamzai, A. S., and J. Shukla, 1999: Relation between Eurasian snow cover, snow depth, and the Indian summer monsoon: An observational study. J. Climate, 12, 3117-3132.

Blanford, H. H., 1884: On the connection of Himalayan snowfall and seasons of drought in India. Proc. Roy. Soc. London, 37, 476-487.

Bottomley, M., C. K. Folland, J. Hsiung, R. E. Newell, and D. E. Parker, 1990: Global Ocean Surface Temperature Atlas. Her Majesty's Stationery Office, 20 pp. and 314 plates.

Chase, T. N., R. A. Pielke, T. G. F. Kittel, R. R. Nemani, and S. W. Running, 1996: Sensitivity of a general circulation model to large scale changes in leaf area index. J. Geophys. Res., 101, 7393-7408.

—, R. A. Pielke Sr., T. G. F. Kittel, R. R. Nemani, and S. W. Running, 2000: Simulated impacts of historical land cover changes on global climate in northern winter. Climate Dyn., 16, 93-105.

Chen, J., B. E. Carlson, and A. D. Del Genio, 2002: Evidence for strengthening of the tropical general circulation in the 1990s. Science, 295, 838-841.

Hamada, J.-I., M. D. Yamanaka, J. Matsumoto, S. Fukao, P. A. Winarso, and T. Sribimawati, 2002: Spatial and temporal variations of the rainy season over Indonesia and their link to ENSO. J. Meteor. Soc. Japan, 80, 285-310.

Helsel, D. R., and R. M. Hirsch, 1995: Statistical Methods in Water Resources. Elsevier, 529 pp.

Kalnay, E., and Coauthors, 1996: The NCEP/NCAR 40-Year Reanalysis Project. Bull. Amer. Meteor. Soc., 77, 437-471.

Kaplan, A., M. A. Cane, Y. Kushnir, A. C. Clement, M. B. Blumenthal, and B. Rajagopalan, 1998: Analyses of global sea surface temperature 1856-1991. J. Geophys. Res., 103, 18 567-18 589.

Kinter, J., III, M. J. Fennessy, V. Krishnamurty, and L. Marx, 2004: An evaluation of the apparent interdecadal shift in the tropical divergent circulation in the NCEP-NCAR reanalysis. J. Climate, 17, 349-361.

Kripalani, R. H., and A. Kulkarni, 1997: Rainfall variability over South-East Asia-Connections with Indian Monsoon and ENSO extremes: New perspectives. Int. J. Climatol., 17, $1155-1168$

_, and — 1998: The relationship between some large-scale atmospheric parameters and rainfall over Southeast Asia: A comparison with features over India. Theor. Appl. Climatol., 59, 1-11.

_ and _ 2001: Monsoon rainfall variations and teleconnections over South and East Asia. Int. J. Climatol., 21, 603-616.

Krishna Kumar, K., M. K. Soman, and K. Rupa Kumar, 1995: Seasonal forecasting of Indian Summer Monsoon Rainfall: A review. Weather, 50 (12), 449-467.

_ B. Rajagopalan, and M. A. Cane, 1999: On the weakening relationship between Indian Monsoon and ENSO. Science, 284, 2156-2159.

Krishnamurthy, V., and B. N. Goswami, 2000: Indian monsoonENSO relationship on interdecadal timescale. J. Climate, 13, 579-595.

Lau, K.-M., and H. T. Wu, 2001: Principle modes of rainfall-SST variability of the Asian summer monsoon: A reassessment of the monsoon-ENSO relationship. J. Climate, 14, 2880-2895.

Liu, X., and M. Yanai, 2001: Relationship between the Indian monsoon rainfall and the tropospheric temperature over the Eurasian continent. Quart. J. Roy. Meteor. Soc., 127, 909-938.

Loader, C., 1999: Local Regression Likelihood. Springer, 290 pp.

Mann, M. E., and J. M. Lees, 1996: Robust estimation of background noise and signal detection in climate time series. Climatic Change, 33, 409-445.

Rasmusson, E. M., and T. H. Carpenter, 1983: The relationship between eastern equatorial Pacific sea surface temperatures and rainfall over India and Sri Lanka. Mon. Wea. Rev., 111, 517-528.

Rupakumar, K., and G. B. Pant, 1997: Climate of South Asia. John Wiley and Sons, $344 \mathrm{pp}$.

Shukla, J., and D. A. Paolino, 1983: The Southern Oscillation and long-range forecasting of summer monsoon rainfall over India. Mon. Wea. Rev., 111, 1830-1837.

Thomson, D. J., 1982: Spectrum estimation and harmonic analysis. Proc. IEEE, 70, 1055-1096.

Trenberth, K. E., D. P. Stepaniak, J. W. Hurrell, and M. Fiorino, 2001: Quality of reanalyses in the Tropics. J. Climate, 14, 1499-1510.

Wang, B., R. Wu, and K.-M. Lau, 2001: Interannual variability of the Asian summer monsoon: Contrasts between the Indian and the western North Pacific-East Asian monsoons. J. Climate, 14, 4073-4089.

Webster, P. J., V. O. Magana, T. N. Palmer, J. Shukla, R. A. Tomas, M. Yanai, and T. Yasunari, 1998: Monsoons: Processes, predictability, and the prospects for prediction. $J$. Geophys. Res., 103 (C7), 14 451-14 510.

Wu, R., and S.-P. Xie, 2003: On equatorial Pacific surface wind changes around 1977: NCEP-NCAR reanalysis versus COADS observations. J. Climate, 16, 167-173.

Xie, P., and P. A. Arkin, 1997: Global precipitation: A 17-year monthly analysis based on gauge observations, satellite estimates, and numerical model outputs. Bull. Amer. Meteor. Soc., 78, 2539-2558.

Xu, J., and J. C. L. Chan, 2001: The role of the Asian-Australian monsoon system in the onset time of El Niño events. J. Climate, 14, 418-433. 